\title{
Comparing the Impact of Intraperitoneal Hydrocortisone With Bupivacaine on Postoperative Pain After Laparoscopic Cholecystectomy
}

\author{
Shahram Amini ${ }^{1,} ;$ Amene Sabzi Sarvestani $^{2}$ \\ ${ }_{1}^{1}$ Department of Anesthesiology and Critical Care, Imam Reza Hospital, Mashhad University of Medical Sciences, Mashhad, Iran \\ ${ }^{2}$ Department Of Surgery, Imam-Ali Educational Hospital, Zahedan University Of Medical Sciences, Zahedan, Iran \\ ${ }^{*}$ Corresponding author: Shahram Amini, Department of Anesthesiology and Critical Care, Imam Reza Hospital, Mashhad University of Medical Sciences, Mashhad, Iran. Tel: +98- \\ 9151417235, Fax: +98-5118525209, E-mail: aminish@mums.ac.ir
}

Received: December 27, 2013; Revised: February 19, 2014; Accepted: March 2, 2014

\begin{abstract}
Background: Postoperative pain is a major complaint following laparoscopic cholecystectomy.
Objectives: The aim of this study was to compare the impact of intraperitoneal hydrocortisone with intraperitoneal bupivacaine on pain relief after laparoscopic cholecystectomy

Patients and Methods: In a double blind clinical trial, 63 candidates for laparoscopic cholecystectomy were randomly allocated to receive intraperitoneal instillation of either $100 \mathrm{mg}$ bupivacaine in $250 \mathrm{~mL}$ normal saline $(\mathrm{n}=32)$ or $100 \mathrm{mg}$ hydrocortisone in $250 \mathrm{~mL}$ normal saline $\left(\mathrm{n}=31\right.$ ) before insufflation of $\mathrm{CO}_{2}$ into the peritoneum for postoperative pain relief. Patients were investigated regarding abdominal and shoulder pain using (visual analog scale) VAS in recovery room and at 6, 12 and 24 hours postoperatively. Patients were also followed regarding postoperative analgesic requirements, nausea and vomiting, and return of bowel function.

Results: Sixty patients completed the study. Patients in the hydrocortisone group had no statistically significant abdominal and shoulder pain scores compared to the bupivacaine group. The patients were similar regarding postoperative analgesic requirements, return of bowel function, nausea and vomiting. No adverse effect was detected in either group.

Conclusions: Intraperitoneal administration of hydrocortisone is as effective as bupivacaine to reduce pain and analgesic requirements after laparoscopic cholecystectomy.
\end{abstract}

Keywords: Cholecystectomy; Postoperative Pain; Intraperitoneal Injection; Bupivacaine; Hydrocortisone

\section{Background}

Laparoscopic cholecystectomy is usually preferred for symptomatic cholelithiasis. Despite many benefits of laparoscopic surgery, many patients complain of pain postoperatively. This may lead to prolonged hospital stay and increased morbidity, which is particularly important in centers performing this operation as a day case procedure (1). In addition to opioids, several methods have been used for pain relief after laparoscopic cholecystectomy including nonopioid analgesics (2), intravenous Paracetamol (3), perioperative parecoxib (4), administration of intraperitoneal local anesthetics alone (5-7) or in combination with nonopioid analgesics $(8,9)$. This might reduce adverse effects of opioids. Furthermore, steroids have also been used successfully for postoperative pain relief in different kinds of surgery (10-12). Sarvestani et al. showed that intraperitoneal hydrocortisone can reduce pain after laparoscopic cholecystectomy without significant adverse effects (13).

\section{Objectives}

The purpose of this study was to compare administration of intraperitoneal glucocorticoids with bupivacaine for pain relief after laparoscopic cholecystectomy. The primary outcome was to compare pain scores between the two groups. The secondary outcomes included postoperative analgesic requirements, frequency of nausea and vomiting, duration of hospital stay, time of return of bowel function, time of unassisted ambulation, and time of oral intake.

\section{Patients and Methods}

After approval of the local ethics committee and informed consent, 63 patients of ASA physical status I-II scheduled for elective laparoscopic cholecystectomy were included in the study. Exclusion criteria were patients with chronic pain other than gallstone disease, use of opioids, tranquilizers, steroids, NSAIDs, and alcohol, patients with acute cholecystitis, allergy to corticosteroids, neuromuscular diseases and bleeding disorders.

After receiving $5 \mathrm{~mL} / \mathrm{kg}$ crystalloids, preoxygenation with $100 \% \mathrm{O}_{2}$ for 3 minutes, $2 \mu \mathrm{g} / \mathrm{kg}$ of fentanyl and 0.05 $\mathrm{mg} / \mathrm{kg}$ of midazolam, anesthesia was induced with thiopental $5 \mathrm{mg} / \mathrm{kg}$ followed by $0.15 \mathrm{mg} / \mathrm{kg}$ of cisatracurium to facilitate endotracheal intubation. Anesthesia was

Copyright (C) 2014, Iranian Society of Regional Anesthesia and Pain Medicine (ISRAPM); Published by Kowsar. This is an open-access article distributed under the terms of the Creative Commons Attribution-NonCommercial 4.0 International License (http://creativecommons.org/licenses/by-nc/4.0/) which permits copy and redistribute the material just in noncommercial usages, provided the original work is properly cited. 
maintained with $60 \% \mathrm{~N}_{2} \mathrm{O}$ in oxygen and propofol $4-6 \mathrm{mg} /$ $\mathrm{kg} / \mathrm{h}$ (to keep the cerebral state index at 40-60) and remifentanil 0.05-0.5 $\mu \mathrm{g} / \mathrm{kg} / \mathrm{min}$ (to maintain mean arterial blood pressure and pulse rates within $20 \%$ of the baseline). All patients received $1 \mu \mathrm{g} / \mathrm{kg}$ fentanyl five minutes before the end of operation for postoperative pain relief.

After receiving the standard anesthesia and before in sufflations of $\mathrm{CO}_{2}$, the patients were allocated randomly (using random table) to receive either instillation of 100 $\mathrm{mg}$ bupivacaine in $250 \mathrm{~mL}$ of normal saline or $100 \mathrm{mg}$ hydrocortisone in $250 \mathrm{~mL}$ normal saline into the peritoneum by a surgical scrub nurse blinded to the study design. Then, patients were positioned in Trendelenburg, anti-Trendelenburg, left and right lateral decubitus and finally supine positions (each for 2 minutes). Nasogastric tube was inserted for all patients after induction and was removed at the end of operation. All surgical procedures were performed by a single surgeon. During laparoscopy, intraabdominal pressure was maintained at $14 \mathrm{mmHg}$. Carbon dioxide was carefully evacuated at the end of operation by manual compression of the abdomen with open trocars. Ten milliliters of bupivacaine $0.25 \%$ was injected in laparoscopy entering sites. Patients were followed by a blinded investigator regarding postoperative abdominal and shoulder pain using VAS based on a 0-10 scale (with 0 indicating no pain and 10 as the most severe pain ever experienced), postoperative analgesic requirements, presence of nausea and vomiting, time of unassisted ambulation, time of oral intake and time of return of bowel function in recovery room and at 6, 12 and 24 hours after the operation. Time of return of bowel function was defined as the time from the end of anesthesia until the presence of bowel sound or first passage of flatus. We administered intramuscular meperidine $0.5 \mathrm{mg} /$ $\mathrm{kg}$ and $1 \mathrm{mg} / \mathrm{kg}$ as rescue analgesic for VAS 4-7, and 8-10, re- spectively. Patients received standard monitoring including pulse rates, noninvasive blood pressure, electrocardiography, respiratory rate, temperature, pulse oximetry, and capnography.

Using SPSS software for Windows, version 15 (SPSS Inc., Chicago, IL, USA), arithmetic mean and standard deviation values for different variables were calculated and statistical analyses were performed for each group. We used independent Student T-test to compare continuous variables with normal distribution, and Chi-square and Mann-Whitney U test for non-continuous variables. P value less than 0.05 was considered significant.

\section{Results}

Sixty patients completed the study. Three were excluded since conversion to open cholecystectomy was necessary because of dense inflammatory adhesions. There were no statistically significant differences between the two groups regarding demographic characteristics and duration of operation (Table 1). The patients were similar regarding factors likely to increase postoperative pain including bile spillage from punctured gallbladder, difficult dissection due to adhesions from previous surgery, bleeding, need to cholangiography, injury to bowels or other organs, and insertion of drain. Abdominal and shoulder pain scores were not significantly different between the two groups and the patients were almost pain free after 12 hours (Tables 2 and 3 ). The patients were similar regarding analgesic requirements in recovery room and 6,12 and 24 hours after the operation (Table 4). The patients were similar regarding the frequency of nausea and vomiting, duration of hospital stay, time of return of bowel function, time of unassisted ambulation, and time of oral intake (Table 5).

\begin{tabular}{lccc}
\hline Table 1. Patients Data and Operation Characteristics & & \\
\hline Data & Bupivacaine Group & Hydrocortisone Group & P Value $^{\text {b }}$ \\
\hline Age, $\mathbf{y}$ & $44.16 \pm 8.39$ & $44.6 \pm 3.32$ & NS \\
Gender, female:male & $18: 12$ & $19: 11$ & NS \\
Weight, $\mathbf{k g}$ & $70.03 \pm 9.60$ & $72.2 \pm 7.94$ & NS \\
Height, cm & $162.2 \pm 5.99$ & $162.0 \pm 5.45$ & NS \\
Duration of operation, min & $94.16 \pm 11.22$ & $93.86 \pm 10.38$ & NS \\
\hline
\end{tabular}

a Data are presented as mean \pm SD or No.

b NS: not significant.

Table 2. Visual Analogue Abdominal Pain Scores in the Two Groups a

\begin{tabular}{lccc}
\hline Group, time & Bupivacaine Group & Hydrocortisone Group & PValue $^{\text {b }}$ \\
\hline In the recovery room, $\mathbf{m g}$ & $4.33 \pm 0.84$ & $4.23 \pm 0.77$ & NS \\
At 6 hours, $\mathbf{m g}$ & $3.33 \pm 0.84$ & $3.13 \pm 0.73$ & NS \\
At 12 hours, $\mathbf{m g}$ & $2.53 \pm 0.57$ & $2.26 \pm 0.58$ & NS \\
At 24 hours, $\mathbf{m g}$ & $1.53 \pm 0.57$ & $1.33 \pm 0.47$ & NS \\
\hline
\end{tabular}

${ }^{\text {a }}$ Data are presented as mean $\pm \mathrm{SD}$.

b NS: not significant. 
Amini Set al.

Table 3. Visual Analogue Shoulder Pain Scores in the Two Groups ${ }^{\text {a }}$

\begin{tabular}{lccc}
\hline Group, time & Bupivacaine Group & Hydrocortisone Group & PValue $^{\mathrm{b}}$ \\
\hline In the recovery room, $\mathbf{m g}$ & $1.93 \pm 0.784$ & $1.93 \pm 0.784$ & NS \\
At 6 hours, $\mathbf{m g}$ & $1.53 \pm 0.507$ & $1.6 \pm 0.498$ & NS \\
At 12 hours, $\mathbf{m g}$ & $1.66 \pm 0.461$ & $1.2 \pm 0.406$ & NS \\
At 24 hours, $\mathbf{m g}$ & $0.53 \pm 0.507$ & $0.63 \pm 0.49$ & NS \\
\hline
\end{tabular}

${ }^{\text {a }}$ Data are presented as mean \pm SD.

b NS: not significant.

\begin{tabular}{lccc}
\hline Table 4. Postoperative Meperidine Requirements in the Two Groups ${ }^{\text {a }}$ & & & \\
\hline Group, time & Bupivacaine Group & Hydrocortisone Group & P Value $^{\text {b }}$ \\
\hline In the recovery room, $\mathbf{m g}$ & $40.00 \pm 20.34$ & $40.00 \pm 20.34$ & NS \\
At 6 hours, $\mathbf{m g}$ & $25.00 \pm 25.42$ & $21.66 \pm 25.2$ & NS \\
At 12 hours, $\mathbf{m g}$ & $15.00 \pm 23.3$ & 00 & NS \\
At 24 hours, $\mathbf{m g}$ & 00 & 00 & NS \\
\hline a
\end{tabular}

a Data are presented as mean \pm SD.

b NS: not significant.

\begin{tabular}{lccc}
\hline \multicolumn{2}{l}{ Table 5. Recovery Variables Between the Two Groups ${ }^{\text {a }}$} & & \\
\hline Group, time & Bupivacaine Group & Hydrocortisone Group & P Value $^{\text {b }}$ \\
\hline Time of oral intake, $\mathbf{h}$ & $12.7 \pm 1.44$ & $12.3 \pm 1.49$ & NS \\
Time of unassisted ambulation, $\mathbf{h}$ & $14.66 \pm 1.47$ & $14.6 \pm 1.49$ & NS \\
Time of bowel function, $\mathbf{h}$ & $18.96 \pm 1.54$ & $18.6 \pm 1.49$ & NS \\
Time of hospital stay, $\mathbf{h}$ - & $27.86 \pm 1.87$ & $27.5 \pm 1.88$ & NS \\
\hline
\end{tabular}

a Data are presented as mean \pm SD.

b NS: not significant.

\section{Discussion}

We demonstrated that intraperitoneal administration of hydrocortisone could decrease pain and analgesic requirements similar to intraperitoneal bupivacaine after laparoscopic cholecystectomy without significant adverse effects. Provision of adequate postoperative pain relief is of considerable importance following day case laparoscopic cholecystectomy (1). Pain after laparoscopic cholecystectomy is affected by several factors including patient demographics, nature of underlying disease, surgical factors, volume of residual gas, and type of gas used for pneumoperitoneum, and the pressure created by the pneumoperitoneum (13-18). A number of techniques were described to reduce post-laparoscopy pain including preincisional infiltration and intraperitoneal instillation of levobupivacaine $0.25 \%$ (19), intraperitoneal ropivacaine and a gas drain (20), intraperitoneal levobupivacaine with epinephrine (21), intraperitoneal application of bupivacaine plus morphine (22), preincisional injection of bupivacaine (23), preemptive intraperitoneal injection of ropivacaine (24) and intraperitoneal lidocaine combined with intravenous or intraperitoneal tenoxicam (25). It is suggested that post- laparoscopic cholecystectomy pain is multifactorial and methods for short-term analgesia cannot improve postoperative functions or shorten hospitalization (26). It has been shown that glucocorticoids can play a crucial role in the regulation of inflammatory responses through both genomic and nongenomic mechanisms and therefore may reduce pain (27). Among corticosteroids, dexamethasone has been used widely to reduce postoperative pain $(21,28,29)$. The mechanism of analgesic effect of steroids is not well known.

Proposed analgesic mechanisms of steroids include suppression of tissue levels of bradikinin and release of neuropeptides from nerve endings, reduction in prostaglandin production inhibiting the synthesis of cyclooxygenase isoform-2 in peripheral tissues and central nervous system; inhibition of other mediators of inflammatory hyperalgesia, for example, tumor necrosis factora, interleukin-17 b, and interleukin-6. Except one study by Sarvestani et al. (13) on laparoscopic cholecystectomy, the effect of intraperitoneal corticosteroids on pain after elective laparoscopic procedures has not been investigated. We assumed that early postoperative pain was mainly 
caused by irritation of the peritoneum, and application of corticosteroids may attenuate this. We used intraperitoneal hydrocortisone successfully to reduce pain following laparoscopic cholecystectomy like intraperitoneal bupivacaine.

In conclusion, our study showed that intraperitoneal injection of hydrocortisone before gas insufflation can reduce postoperative pain similar to intraperitoneal bupivacaine with no significant postoperative adverse effects in laparoscopic cholecystectomy.

\section{Acknowledgements}

We would like to thank Imam Ali Hospital personnel in general operating room and surgical ward for their contribution in this study.

\section{Authors' Contributions}

Amene Sabzi Sarvestani developed the original idea and the protocol, collected data, and wrote the manuscript. Shahram Amini contributed to the development of the protocol, analyzed and interpreted data, wrote the manuscript, and supervised the study.

\section{Fundig/Support}

This study was financially supported by the Research Deputy of Zahedan University of Medical Sciences, Zahedan, Iran.

\section{References}

1. Boddy AP, Mehta S, Rhodes M. The effect of intraperitoneal local anesthesia in laparoscopic cholecystectomy: a systematic review and meta-analysis. Anesth Analg. 2006;103(3):682-8.

2. Abdulla S, Eckhardt R, Netter U, Abdulla W. A randomized, double-blind, controlled trial on non-opioid analgesics and opioid consumption for postoperative pain relief after laparoscopic cholecystectomy. Acta Anaesthesiol Belg. 2012;63(1):43-50.

3. Salihoglu Z, Yildirim M, Demiroluk S, Kaya G, Karatas A, Ertem $\mathrm{M}$, et al. Evaluation of intravenous paracetamol administration on postoperative pain and recovery characteristics in patients undergoing laparoscopic cholecystectomy. Surg Laparosc Endosc Percutan Tech. 2009;19(4):321-3.

4. Akaraviputh T, Leelouhapong C, Lohsiriwat V, Aroonpruksakul S. Efficacy of perioperative parecoxib injection on postoperative pain relief after laparoscopic cholecystectomy: a prospective, randomized study. World J Gastroenterol. 2009;15(16):2005-8.

5. Khan MR, Raza R, Zafar SN, Shamim F, Raza SA, Pal KM, et al. Intraperitoneal lignocaine (lidocaine) versus bupivacaine after laparoscopic cholecystectomy: results of a randomized controlled trial.J Surg Res. 2012;178(2):662-9.

6. Beqiri AI, Domi RQ, Sula HH, Zaimi EQ, Petrela EY. The combination of infiltrative bupivacaine with low-pressure laparoscopy reduces postcholecystectomy pain. A prospective randomized controlled study. Saudi Med J. 2012;33(2):134-8.

7. El-Labban GM, Hokkam EN, El-Labban MA, Morsy K, Saadl S, Heissam KS. Intraincisional vs intraperitoneal infiltration of local anaesthetic for controlling early post-laparoscopic cholecystectomy pain. J Minim Access Surg. 2011;7(3):173-7.

8. Golubovic S, Golubovic V, Cindric-Stancin M, Tokmadzic VS Intraperitoneal analgesia for laparoscopic cholecystectomy: bupivacaine versus bupivacaine with tramadol. Coll Antropol. 2009;33(1):299-302.
9. Roberts KJ, Gilmour J, Pande R, Nightingale P, Tan LC, Khan S. Efficacy of intraperitoneal local anaesthetic techniques during laparoscopic cholecystectomy. Surg Endosc. 2011;25(11):3698-705.

10. Choi YS, Shim JK, Song JW, Kim JC, Yoo YC, Kwak YL. Combination of pregabalin and dexamethasone for postoperative pain and functional outcome in patients undergoing lumbar spinal surgery: a randomized placebo-controlled trial. Clin J Pain. 2013;29(1):9-14

11. Buland K, Zahoor MU, Asghar A, Khan S, Zaid AY. Efficacy of single dose perioperative intravenous steroid (dexamethasone) for postoperative pain relief in tonsillectomy patients. J Coll Physicians Surg Pak. 2012;22(6):349-52.

12. Safavi M, Honarmand A, Habibabady MR, Baraty S, Aghadavoudi $\mathrm{O}$. Assessing intravenous ketamine and intravenous dexamethasone separately and in combination for early oral intake, vomiting and postoperative pain relief in children following tonsillectomy. Med Arh. 2012;66(2):111-5.

13. Sarvestani AS, Amini S, Kalhor M, Roshanravan R, Mohammadi $\mathrm{M}$, Lebaschi AH. Intraperitoneal hydrocortisone for pain relief after laparoscopic cholecystectomy. Saudi J Anaesth. 2013;7(1):14-7.

14. Mirzai H, Tekin I, Alincak H. Perioperative use of corticosteroid and bupivacaine combination in lumbar disc surgery: a randomized controlled trial. Spine (Phila Pa 1976). 2002;27(4):343-6.

15. Kopacz DJ, Lacouture PG, Wu D, Nandy P, Swanton R, Landau C The dose response and effects of dexamethasone on bupivacaine microcapsules for intercostal blockade (T9 to T11) in healthy volunteers. Anesth Analg. 2003;96(2):576-82.

16. Stan T, Goodman EJ, Bravo-Fernandez C, Holbrook CR. Adding methylprednisolone to local anesthetic increases the duration of axillary block. Reg Anesth Pain Med. 2004;29(4):380-1.

17. Koc M, Ertan T, Tez M, Kocpinar MA, Kilic M, Gocmen E, et al Randomized, prospective comparison of postoperative pain in low- versus high-pressure pneumoperitoneum. ANZ J Surg. 2005;75(8):693-6.

18. Ekici Y, Bozbas H, Karakayali F, Salman E, Moray G, Karakayali H et al. Effect of different intra-abdominal pressure levels on QT dispersion in patients undergoing laparoscopic cholecystectomy. Surg Endosc. 2009;23(11):2543-9.

19. Bisgaard T, Kehlet H, Rosenberg J. Pain and convalescence after laparoscopic cholecystectomy. Eur J Surg. 20 01;167(2):84-96.

20. Sandhu T, Yamada S, Ariyakachon V, Chakrabandhu T, Chongruksut W, Ko-iam W. Low-pressure pneumoperitoneum versus standard pneumoperitoneum in laparoscopic cholecystectomy, a prospective randomized clinical trial. Surg Endosc. 2009;23(5):1044-7.

21. Wills VL, Hunt DR. Pain after laparoscopic cholecystectomy. Br J Surg. 2000;87(3):273-84.

22. O'Boyle CJ, deBeaux AC, Watson DI, Ackroyd R, Lafullarde T, Leong JY, et al. Helium vs carbon dioxide gas insufflation with or without saline lavage during laparoscopy. Surg Endosc. 2002;16(4):620-5.

23. Louizos AA, Hadzilia SJ, Leandros E, Kouroukli IK, Georgiou LG Bramis JP. Postoperative pain relief after laparoscopic cholecystectomy: a placebo-controlled double-blind randomized trial of preincisional infiltration and intraperitoneal instillation of levobupivacaine 0.25\%. Surg Endosc. 2005;19(11):1503-6.

24. Readman E, Maher PJ, Ugoni AM, Gordon S. Intraperitoneal ropivacaine and a gas drain: effects on postoperative pain in laparoscopic surgery. J Am Assoc Gynecol Laparosc. 2004;11(4):486-91.

25. Ng A, Swami A, Smith G, Robertson G, Lloyd DM. Is intraperitoneal levobupivacaine with epinephrine useful for analgesia following laparoscopic cholecystectomy? A randomized controlled trial. Eur J Anaesthesiol. 2004;21(8):653-7.

26. Hernandez-Palazon J, Tortosa JA, Nuno de la Rosa V, GimenezViudes J, Ramirez G, Robles R. Intraperitoneal application of bupivacaine plus morphine for pain relief after laparoscopic cholecystectomy. Eur J Anaesthesiol. 2003;20(11):891-6.

27. Lepner U, Goroshina J, Samarutel J. Postoperative pain relief af ter laparoscopic cholecystectomy: a randomised prospective double-blind clinical trial. Scand J Surg. 2003;92(2):121-4. 


\section{Amini Set al.}

28. Maestroni U, Sortini D, Devito C, Pour Morad Kohan Brunaldi F, Anania G, Pavanelli L, et al. A new method of preemptive analgesia in laparoscopic cholecystectomy. Surg Endosc. 2002;16(9):1336-40.
29. Elhakim M, Amine H, Kamel S, Saad F. Effects of intraperitoneal lidocaine combined with intravenous or intraperitoneal tenoxicam on pain relief and bowel recovery after laparoscopic cholecystectomy. Acta Anaesthesiol Scand. 2000;44(8):929-33. 